\title{
Improving Mental Health Access in Central and Eastern Europe: A Review of current systems
}

E. Steele (Elizabeth Steele), S. Szydlowski (Steven Szydlowski)

University of Scranton, PA., Master of Health Administration Graduate

Program, USA

\section{E-mail address:}

Elizabeth.Steele@scranton.edu

\section{Reprint address:}

Elizabeth Steele

University of Scranton

Scranton Hall

Scranton, PA. 18510

USA

Source: Clinical Social Work and Health Intervention Pages: $44-47$
Volume: 10

Issue: 1

\section{Reviewers:}

Arab Naz

University of Malakand Chakdara Khyber Pakhtunkhwa, Pakistan

Selvaraj Subramanian

SAAaRMM, Kuala Lumpur, Malaysia

\section{Key words:}

Mental Health. Slovakia. Czech Republic. World Health Organization. Primary Care.

\section{Publisher:}

International Society of Applied Preventive Medicine i-gap

CSWHI 2019; 10(1): 44 - 47; DOI 10.22359/cswhi_10_1_07 @ 2019 Clinical Social Work and Health Intervention

\section{Abstract:}

Objective: This paper outlines the current access of Mental Health services in Slovakia. Examining information from the World Health Organization and other peer-reviewed articles, the author outlines the current Mental Health system and identifies areas of improvement. 
Methods: This paper is a secondary resource on the access of Mental Health and the implications of stagnate change within Central Eastern Europe.

Results: The various ministries Slovakia should change their current Mental Health policy. The country should also increase efforts to integrate Mental Health into the primary care setting, as well as increase documentation of available statistics for Mental Health professionals and future research opportunities.

Conclusion: This research indicated that Slovakia struggles with up-todate documentation of Mental Health statistics, as well as financial viability of services. Demonstrating that access to care remains an issue.

\section{Introduction}

Mental Health access is a topic that is often put aside when "more pressing" topics hit the media. Mental Health can be defined as any neuropsychiatric disease that impairs a person's mental state and affects their daily living (World Health Organization 2014). This can be anything from major or minor depression, major or minor anxiety, to schizophrenia, etc. Mental Health is not only an issue in central and Eastern Europe but has also been a topic of discussion all over the world. Globally, 120 million people suffer from depression and 24 million from schizophrenia (Chelala, Cesar 2013). The World health organization states that about 1 in 4 people have been affected by one type of Mental Health disorder. This accounts for about 450 million people being affected, with depression being the 4th leading cause of burden of disease. The World Health Organization states that by 2020 depression will increase to the 2nd leading cause of burden of disease (World Health Organization 2001). Addressing Mental Health issues in a growing global concern. Since about $90 \%$ of documented suicides are due to a Mental Health issues and suicides account of $17.6 \%$ of all deaths; if left unattended these rates will only rise (World population review 2018).

\section{Demographics}

The Slovakia Republic, similar to other countries around the world, is struggling to adapt to the needed increase in access for Mental Health. As of 2016, there were 9.7 suicides per 100,000 people in the Slovakia Republic (Organizations for Economic Cooperation and Development 2016). Mental Health is ranked the second leading cause of death in Europe among the age group of 15-29-year-old individuals; second only to road traffic accidents. In 2017, the World Health Organization stated that although many Europeans suffer from Mental Health, three out of four people suffering from major depression are not receiving adequate treatment.

\section{Mental-Health Services}

Mental Health is $26 \%$ burden of disease for the country of Slovakia. There is a Mental Health policy and plan, however, due to unknown restraints, plans are not updated yearly. This inability to stay updated with current policies can cause delays in implantation and delivery of care. During the 2008 revision of Slovakia's Mental Health Plan, Slovakia hoped to increase the timeliness for implementation and strove to integrate Mental Health into the primary care setting (World Health Organization 2011). The 
impact of these initiatives will be discussed further in the article.

\section{Barriers to Mental Health}

There are three main barriers identified by the State Members themselves that highlight a global struggle for better access to care. These barriers include: insufficient funding; insufficient availability of Mental Health professionals; and as stated before, the stigma that still surrounds Mental Health today (Stefan Lassan 2017).

\section{Solutions and opportunities}

The first area of opportunity is to conduct more research on Mental Health trends within Slovakia, as well as observe how other organizations and countries are assessing their need and moving forward with action.

The Czech Republic is a great example of a country who is also struggling with Mental Health but trying to mitigate the barriers to access. With 20 pilot organizations being placed around the country, they are trying to find the solutions that best fit their society and are the most financially viable. Since their main target is to increase the quality of life for patients, they are breaking these pilot organizations into an 8-step plan. A few of these steps include developing standards and methodology for quicker care and access for patients; increasing research and education; a closer look at sustainable funding; interdepartmental cooperation. Two main targets of these organizations will be to focus on sustainable funding and an improved financial model. Since one of the barriers that State members have identified was lack of funding, Czech Republic is looking into an outpatient setting for Mental Health disorders. Stefan Lassan stated that it costs about 5 million koruna to house 10 patients in hospital beds, but the same amount of money the system can house 100 outpatients (Stefan Lassan 2017). This is an example of taking the money that the country is already using and thinking of new and innovative ways of using that money.

\section{Primary Care Action}

Using a general practitioner, in a primary care setting will improve Mental Health access. Developing comprehensive based programs to work with community networks, will help engage the population on the importance of Mental Health and reduce the stigma associated with it. Focusing on the physical health such as nutrition and exercise will also help the patients increase their chance of recovery. The Mental Health Foundation found that people who were obese had a $55 \%$ increased risk of developing depression and people who were depressed had a 58\% increase in the risk of becoming obese. (Mental Health Foundation 2018) Having general practitioners focus on the importance of nutrition and exercise with all patients will help to decrease the prevalence of Mental Health disorders. Furthermore, general practitioners can treat patients who are unable to seek psychiatric trained physicians due to the lack of qualified personnel. Since one in three general practitioners' encounters with patients involved Mental Health, this should be something that physicians are discussing throughout their education and professional career. (Mind Charity 2016).

\section{Conclusion}

With the increased prevalence in Mental Health as well as the suicide rates associated with Mental Health, it is imperative that action be taken to give patients adequate access to care. Annually or bi-annually updating Mental Health policy, reducing the stigma throughout health care facilities and the general population, would improve the delivery of care. Addressing both physical and Mental Health will help patients better 
understand their diagnosis and provide them with better outcomes. If left untreated, depression will rise to the 2 nd leading cause of burden of disease and therefore those affected will be $58 \%$ more likely to become obese. Obesity, leading into another issue we struggle with globally, also causes issues for individual health and longevity. Using the general practitioners and increasing financial resources will be the pillars of success for tackling these issues in the future.

\section{References:}

1. CHELALA C (2013) Movement for Global Mental Health. Retrieved from http://www. globalmentalhealth.org/untreated-mental-health-issues-global-reality .

2. LASSAN S (2017) The present state of Mental Health Care in Slovakia. Slovak Psychiatric Association. Retrieved from: http:// www.psychiatry.sk/cms/File/2018/GR\%20
Lassan\%20Smolenice_castle_12_11_17. pdf.

3. MENTAL HEALTH FOUNDATION (2018) Diet and Mental Health. Mental Health Foundation. Retrieved from https:// www.mentalhealth.org.uk/a-to-z/d/dietand-mental-health .

4. MIND CHARITY (2016) Mental Health in Primary Care: A briefing for clinical commissioning

5. groups. Retrieved from https://www.mind. org.uk/media/4556511/13296_primary-care-policy_web_op.pdf.

6. ORGANISATION FOR ECONOMIC CO-OPERATION AND DEVELOPMENT (2016) Retrieved from https://data.oecd.org/ healthstat/suicide-rates.htm.

7. WORLD HEALTH ORGANIZATION (2004) Burden of Disease. Retrieved from http://www.who.int/foodsafety/foodborne disease/Q\&A.pdf. 